\title{
Peer Victimization and Depressive Symptoms Among Rural-to-Urban Migrant Children in China: The Protective Role of Resilience
}

\author{
Zhi Ye', Lihua Chen ${ }^{1}$, Sayward E. Harrison², Haiying Guo ${ }^{1}$, Xiaoming $\mathrm{Li}^{2}$ and \\ Danhua Lin ${ }^{1 *}$ \\ ${ }^{1}$ Institute of Developmental Psychology, Beijing Normal University, Beijing, China, ${ }^{2}$ Department of Health Promotion, \\ Education, and Behavior, University of South Carolina, Columbia, SC, USA
}

OPEN ACCESS

Edited by: Natasha Kirkham, Cornell University, USA

Reviewed by: Lei Chang,

University of Macau, Macau Hideko Hamada Bassett, George Mason University, USA

*Correspondence:

Danhua Lin

danhualin@bnu.edu.cn

Specialty section:

This article was submitted to

Developmental Psychology,

a section of the journal

Frontiers in Psychology

Received: 06 April 2016 Accepted: 22 September 2016

Published: 04 October 2016

Citation:

Ye Z, Chen L, Harrison SE, Guo H,

Li $X$ and Lin D (2016) Peer

Victimization and Depressive Symptoms Among Rural-to-Urban Migrant Children in China: The Protective Role of Resilience.

Front. Psychol. 7:1542.

doi: 10.3389/fpsyg.2016.01542
Peer victimization can have a profound effect on children's wellbeing and is a known risk factor for depression in childhood. Migrant children experience peer victimization at higher rates than non-migrant peers; however, limited research has examined psychological factors that may serve to reduce depression risk for this group. In particular, no studies have yet investigated whether resilience, including personal characteristics, and a strong social support network, may moderate the relationship between peer victimization and depressive symptoms for migrant children. This study utilized a latent interaction model to examine the effect of resilience on the relationship between peer victimization and depressive symptoms among 721 rural-to-urban migrant children in Beijing, China. Results indicated that peer victimization was positively associated with depressive symptoms. Resilience was found to be a protective factor for depressive symptoms and also mitigated the effects of peer victimization on depressive symptoms. Exploratory analyses suggest that enrollment in private migrant schools may be linked with poorer psychosocial outcomes for Chinese migrant children. Strengthening the internal resilience and social supports for all migrant children may be an effective strategy to lower their risk for depression. Implications for intervention are discussed.

\section{Keywords: peer victimization, resilience, depressive symptoms, migrant children, moderate effect}

\section{INTRODUCTION}

Being victimized has negative and far-reaching effects on children and is a risk factor for internalizing and externalizing problems, poor school achievement, and even suicide (Sentse et al., 2013). In this study, we examine the relationships among peer victimization, resilience, and depressive symptoms for children who migrate with their parents from rural areas to Beijing, China. First, we investigate whether peer victimization and resilience are significant predictors of depressive symptoms. Next, we explore the protective effect of resilience on the relationship between peer victimization and depressive symptoms.

Since the late 1970s, China has experienced increases in economic disparity and rapid urbanization that have resulted in an unprecedented growth of rural-to-urban migration. This migration typically follows a pattern of movement from the western and central inlands of China 
(e.g., Sichuan, Henan, Anhui, and Hunan provinces) to eastern coastal locations (i.e., Beijing, Shanghai, and Guangdong provinces). Migrants move to urban centers in search of better jobs, increased educational opportunity, and improved living conditions. However, they frequently find themselves residing in unsanitary, overcrowded dormitories or in shared accommodations and working in physically demanding jobs such as manual labor, factory work, or service work where they are paid low wages (Wong and Song, 2008). Adults who migrate to urban centers often bring their children with them (Chen et al., 2009). Thus the number of Chinese migrant children who are residing in urban areas has substantially increased in recent years ( $\mathrm{Hu}$ et al., 2014). In 2013, approximately 35.8 million migrant children and adolescents were estimated to reside in China, representing a $41.4 \%$ increase since 2005 and accounting for $12.8 \%$ of the current child population in China (Mao and Zhao, 2012; AllChina Women's Federation, 2013; Hu et al., 2014). Beijing is currently estimated to have approximately 366,000 migrant primary-school-aged children, accounting for about $44.6 \%$ of all students enrolled in primary schools (Beijing Municipal Bureau of Statistics and Nbs Survey Office in Beijing, 2015).

Children who migrate to host cities with parents are likely to encounter unique challenges when compared to their nonmigrant counterparts. Under China's Household Registration System (i.e., hukou system), Chinese citizens are categorized into either an urban or rural residency status. Migrant families maintain their rural residential status after relocating to an urban area. Because public school enrollment is contingent upon local legal residency, children of migrant workers are frequently denied enrollment in local public schools. While some parents are able to gain entry for their children into public schools through paying special fees or other means, most must send their children to inexpensive private migrant schools that are often constructed and staffed by migrant workers themselves (Chen and Feng, 2013).

In Beijing, these private migrant schools are typically located within migrant enclaves and have limited access to educational resources (Chen et al., 2009). Most private migrant schools do not receive government subsidies as they operate informally and are typically staffed by under-qualified teachers, offer very limited curricula, and operate with poor facilities (Goodburn, 2009; Chen and Feng, 2013). Moreover, even migrant children who are able to enroll in public schools face numerous challenges; most are still ineligible to take middle or high school entrance examinations in Beijing and must return to their hometowns if they wish to seek further education (Wu et al., 2012). Lack of legal residency also means that Chinese migrant children residing in urban areas frequently have limited access to health care and other social services (Liang and Chen, 2007; Zhang et al., 2010). These sociocultural systems interact with and shape children's behavioral and psychological health (Bronfenbrenner, 1979, 1989) and pose particular challenges for migrant children.

Within this context of marginalization and limited resources, migrant children must navigate the complex processes of acculturation and adaptation. The acculturation process has been theorized to consist of two distinct experiences: (1) sociocultural adjustment to a new set of customs and cultural expectations, and (2) psychological changes one's cultural identity, attitudes, and social behaviors flex and bend (Berry, 2003; Phinney, 2003). This process frequently yields "acculturation stress" (Berry et al., 2006) that challenges multiple domains of functioning including emotional wellbeing, social functioning, and adaptive skills (Wang and Mesman, 2015). Within their new environments, migrant children are often perceived to be "outsiders" and may have difficulty adapting into their new urban society (Hu et al., 2014).

In fact, the impact of the migrant experience on the psychological wellbeing of Chinese children has been extensively studied in the past decade, with results suggesting that compared with non-migrant urban peers, migrant children suffer from a higher prevalence of mental health problems, including depression, social anxiety, and problem behavior (Li et al., 2008; Lin et al., 2009). Both residential and school mobility represent significant ecological transitions for children, and mobility is a known risk factor that may negatively impact the ability of children to develop positive relationships and achieve academic success, especially for low-income children or children living in non-traditional family structures (Tucker and Long, 1998; Temple and Reynolds, 1999). Due to their status as "newcomers" in their social environments (e.g., school, neighborhood), migrant children are often discriminated against in urban areas because they are believed to have undesirable characteristics (e.g., low socioeconomic status, accent, undesirable appearance, unfamiliar customs, or behaviors) that mark them as different and cause them to be devalued, rejected, excluded, or victimized by peers (Guo, 2007; Chen et al., 2014). Tan (2010) investigated 758 migrant children from two cities in China and found that approximately $21.8 \%$ of migrant children were involved in bullying, significantly higher than the prevalence of $14.9 \%$ among the general child population in China (Zhang, 2002).

Peer victimization is defined as "the experience among children of being a target of the aggressive behavior of other children" (Hawker and Boulton, 2000). It can take many forms, including physical harassment, verbal harassment, relational aggression, and property-related victimization. While such incidents are relatively common during childhood and early adolescence, peer victimization poses significant threats to children's wellbeing, especially when chronic (Mynard and Joseph, 2000). Previous research has consistently reported that, compared with non-victimized peers, children who experience peer victimization are at-risk for a number of psychological difficulties, including problem behavior, anxiety, loneliness, poor life satisfaction, and low self-esteem (Diler et al., 2003; Gu et al., 2010; Liu et al., 2014). Operating in a negative feedback loop, such emotional difficulties can contribute to increased levels of acculturation stress and can cause further isolation for affected children and families.

Among the various types of internalizing problems, peer victimization is most strongly associated with depressive symptoms in childhood, especially during middle childhood (Hawker and Boulton, 2000; Ghoul et al., 2013; Roeder et al., 2014). There is evidence that the experience of peer victimization predicts the development of negative cognitions and reductions in positive cognitions, and that this, in turn, contributes to 
the development of depression (Sinclair et al., 2012). Both cross-sectional and longitudinal studies have suggested a strong association between peer victimization and depression (Seals and Young, 2003; Hong and Espelage, 2012; Cole et al., 2014). Being an occasional target of bullying has been found to be associated with risk of depressive symptoms, while frequent exposure to victimization is linked with risk for clinical depression (Klomek et al., 2007). Thus peer victimization may display a dose-response relationship with negative mental health outcomes, with higher doses of victimization yielding higher levels of mental health problems (Evans et al., 2014). Longitudinal studies have also found peer victimization to be a significant and positive predictor of depressive symptoms among children over time (Bond et al., 2001; Snyder et al., 2003; Schwartz et al., 2005). For instance, being a victim of school bullying at the age of 15 predicted higher levels of self-reported depressive symptoms throughout later adolescence and early adulthood, suggesting that the effects of bullying are serious and long lasting (Due et al., 2009). The link between victimization and depression has also been documented for Chinese children. A recent study investigated associations between peer victimization and psychosocial adjustment among 1,767 Chinese children, with results indicating that peer victimization significantly predicted the experience of depressive symptoms (Ji et al., 2011). However, data is limited regarding the relationship between peer victimization and depressive symptoms for rural-to-urban migrant children in China.

Due to the heightened risks faced by migrant children, there is a need to identify protective factors that can help this population adapt to their new environments in a successful manner and manage the accompanying psychological challenges that acculturation encompasses. Such protective mechanisms can broadly be characterized as facets of "resilience." While resilience has no universally accepted definition, psychological resilience is typically thought to be a dynamic process that allows an individual to positively adapt in the face of adversity (Luther et al., 2000; Li et al., 2015). Resilience thus serves as a protective process that can buffer the deleterious effects of individual and/or contextual risk factors (Fincham et al., 2009; Masten and Narayan, 2012). In developmental literatures, the process of resilience enables an individual to adapt in the face of risk, trauma and other aversive life circumstances, and has typically been conceptualized as operating at three broad levels: at the community level (e.g., neighborhood characteristics, social supports), at the family level (e.g., parental warmth, close caregiver relationship), and at the child level (e.g., hardy personality, intelligence) (Werner and Smith, 1982; Garmezy, 1985). The protective ability of individual characteristics has been well examined among children exposed to various adversities, and multiple protective factors have been identified including a hardy personality, strong self-efficacy, hope for the future, self-enhancing cognitions, positive coping skills, and positive emotion (Bonanno, 2004).

Multiple studies have used moderation analysis to examine the ability of resilience to confer protection against the adverse effects of contextual risk. Wingo et al. (2010) found that resilience moderated depressive symptom severity among 792 American adults exposed to childhood trauma. Specifically, given similar levels of trauma exposure, individuals with high resilience displayed significantly lower depressive symptoms than those with low resilience (Wingo et al., 2010). Similarly, CampbellSills et al. (2006) examined the psychological wellbeing of 132 American college students and also found that resilience was a moderator in the relationship between emotional neglect in childhood and current psychiatric symptoms. While resilience has garnered a broad literature base through investigations with Western populations, efforts to investigate resilience with Eastern populations are more limited. Lee and Cranford (2008) found that resilience played a protective role in buffering the negative effects of risk factors on depressive symptoms among children of alcoholic parents in Korea. Peng et al. (2012) investigated 2069 Chinese medical students and reported that resilience moderated the relationship between negative life events and mental health problems. In addition, resilience was found to moderate the effects of negative events on adolescent depressive symptoms for 2,250 Chinese children and adolescents 6 months after experiencing the devastating Wenchuan earthquake (Zhu et al., 2012). While such studies have sought to identify the protective influence of resilience on depressive symptoms among at-risk children and adolescents, little work has yet examined the ability of resilience to moderate the relationship between peer victimization and depressive symptoms, particularly among rural-to-urban migrant children in China.

The current study attempts to fill these gaps by investigating the following research questions: (1) Is peer victimization a significant predictor of depressive symptoms among ruralto-urban migrant children in China? (2) Does resilience in migrant children moderate the relationship between peer victimization and depressive symptoms? Based on previous work, we hypothesized that peer victimization would be a significant predictor of migrant children's level of depressive symptoms. Furthermore, we hypothesized that resilience would moderate the relationship between peer victimization and depressive symptoms, such that the negative effects of peer victimization on depressive symptoms would be weaker among migrant children with higher levels of resilience.

\section{MATERIALS AND METHODS}

\section{Participants and Procedure}

In the current study, migrant children from the 4th, 5th and 6th grades of three primary schools (i.e., two traditional public schools and one private migrant school) in the Daxing district of Beijing were recruited for participation. The research team initially worked with school principals to generate lists of eligible migrant children. The eligibility criteria for migrant children included the following: (1) no household register (i.e., hukou) in Beijing and (2) temporarily living with parents who have migrated to Beijing for employment for more than 3 months. A total of 721 adolescents were recruited for the study. The sample included $384(53.3 \%)$ migrant adolescents attending traditional public school and $337(46.7 \%)$ migrant children attending a private migrant school. Of the 721 participants, $277(38.4 \%)$ were girls and $444(61.6 \%)$ were boys. The grade 
distribution was as follows: 251 (34.8\%) were enrolled in 4th grade, $221(30.7 \%)$ were enrolled in 5th grade and $246(34.1 \%)$ were enrolled in 6th grade. Four of them did not report their grade. The mean age estimate for children enrolled was 10.22, $S D=1.02$ (The Ministry of Education of the People's Republic of China, 2014).

After acquiring permission from school principals to conduct the survey in their schools, eligible children who agreed to participate were asked to complete a battery of self-administered questionnaires. Children completed the questionnaires in a classroom, and trained interviewers (i.e., 15 psychology graduate students) circulated among them to answer any questions or provide necessary clarification. Each child received an ageappropriate gift (i.e., toy or school supplies) at the completion of the survey as a token of appreciation. All study procedures were approved by the Institutional Review Board (IRB) at Beijing Normal University.

\section{Measures \\ Peer Victimization}

Peer victimization was measured by creating a modified multidimensional scale derived from the Chinese version of the Multidimensional Peer Victimization Scale (Zhang et al., 2009), the Children's Peer Victimization Scale (Dong, 2007), and the Social Experience Questionnaire-Self Report (Crick and Bigbee, 1998). The modified scale contains 18 items that assessed physical victimization (three items; e.g., "Other kids hurt me physically in some way"), relational victimization (seven items; e.g., "Some kids tried to get me into trouble with my friends"), verbal victimization (five items, e.g., "Other kids swore at me") and property victimization (three items; e.g., "Some kids tried to break or steal something of mine"). Each item was rated on a 4-point scale, ranging from 1 (never) to 4 (a lot). Confirmatory factor analysis indicated that the four-factor model demonstrated a good fit to the data: $\chi^{2} / d f=1.64$, CFI $=0.94$, TLI $=0.93$, RMSEA $=0.05$. The Cronbach's $\alpha$ coefficients were 0.80, 0.89, $0.82,0.66$, respectively, for subscales and 0.93 for the full scale.

\section{Resilience}

The 27-item Resilience Scale for Chinese Adolescents (RSCA, Hu and Gan, 2008) was used to evaluate children's resilience. The scale measures the ability of an adolescent to cope with stress and adversity and has been used widely in research on Chinese children's resilience (Wang et al., 2014; Zhang and Tian, 2014). The questionnaire contains two subscales that measure personal assets and social resources. The personal assets subscale measures an individual's internal capacity to cope with difficulties, while the social resources subscales measure an individual's perceived support from peer and family members and the competency for support seeking when encountering adversity. The following are examples of items: "The experience of frustration made me more mature" and "I believe adversity can inspire people." Responses to the items are given on a 5-point Likert scale ( $1=$ strongly disagree, 2 = disagree most of the time, 3 = agree sometimes, $4=$ agree most of time, $5=$ strongly agree), with higher scores indicating higher levels of resilience. In the current study, the
Cronbach's alpha coefficients of the personal assets and social resources subscales were 0.79 and 0.78 , respectively, and the full scale's Cronbach's alpha was 0.86 , indicating good internal consistency.

\section{Depressive Symptoms}

Depressive symptoms were assessed with the self-reported Center of Epidemiological Studies Depression Scale for Children (CESDC), developed by Fendrich et al. (1990). CES-DC contains 20 items and measures symptoms associated with depression. Children rate each item with regard to how frequently they have experienced the symptom in the previous week. Sample items from the measure include: "I did not feel like eating and my appetite was poor" and "I felt sad." The response options rated each item on a 4-point scale ranging from 0 (not at all) to 3 (a lot) with higher scores indicating higher levels of depressive symptoms. The scale displayed good internal consistency ( $\alpha=0.83)$ for the sample in the current study. In order to meet standards for constructing a latent variable interaction model, item parceling was used to create a latent variable for depressive symptoms. In this study, the Cronbach's $\alpha$ of the three subscales were $0.54,0.57$, and 0.65 , while the internal consistency estimate of the full scale was 0.83 .

\section{Statistical Analysis}

Statistical analyses were performed using SPSS 22.0 and Mplus7.1 (Muthén and Muthén, 1998-2012). First, descriptive statistics, including means, standard deviations, and bivariate correlations, were calculated by group (i.e., private migrant school, public school). Second, hypotheses were tested using structural equation modeling to assess the latent variable interaction effect estimation of peer victimization and resilience on depressive symptoms. The interaction model was tested using the latent variable interaction approach described by Klein and Moosbrugger (2000). A two-step approach was used to model the latent variable interaction. Firstly, peer victimization and resilience were used to jointly predict depressive symptoms (Model 1). Only linear effects of the predictors were considered in this conventional structural equation model. Next, the latent moderated structural equation method was used to examine the latent interaction effect between peer victimization and resilience on depressive symptoms (Model 2).

The technique of item parceling was employed to construct the measurement model of depression for two reasons. First, compared to item-level data, parceling could provide more stable factor solutions (Little et al., 2002). Second, item parceling can reduce the estimate parameters and the likelihood of residuals being correlated, which can further reduce the measurement error of the model. Three parcels for depression were created based on the method of item-to-construct balance (Landis et al., 2000). To do this, CES-DC was subjected to a factor analysis in which a single-factor solution was specified. Then, the highest and lowest factor loadings were combined as a set. The construct for depression was unidimensional in nature, which indicated that some of the pitfalls of item parceling (e.g., misrepresentation of the factor model) were avoided in this study (Chang and 
Edwards, 2015). Item parceling was not used for the measures of peer victimization and resilience because they are both multidimensional constructs that are well represented by the original subscales.

To enhance the interpretability of results, we used the Robust Maximum Likelihood estimator as it does not require normal distribution of variables, and standardized all indicators before running the analyses. In addition, we used the Root Mean Square Error of Approximation (RMSEA; 0.05 or below indicating excellent fit, $0.05-0.08$ reflecting an acceptable fit), Comparative Fit Index (CFI; 0.95 or above indicating excellent fit, 0.90-0.95 reflecting an acceptable fit), and TuckerLewis Index (TLI; 0.95 or above indicating excellent fit, 0.90-0.95 reflecting an acceptable fit) to test model fit for all models. Gender and grade were controlled as potential confounders. However, none of these variables were found to significantly predict the outcome, so they were dropped from the analysis.

Multiple-group analysis was also employed in an exploratory analysis to test for statistically significant differences in the structural parameters across groups (i.e., children enrolled in private migrant school vs. public school).

\section{RESULTS}

\section{Descriptive Statistics by School Group and Correlates of Peer Victimization, Resilience, and Depressive Symptoms}

As shown in Table 1, migrant children currently enrolled in the private migrant school reported significantly higher levels of victimization, more depressive symptoms, and lower level of resilience than migrant children enrolled in the traditional public schools.

Pearson correlation coefficients among all observed variables are shown in Table 2. Peer victimization was positively associated with depressive symptoms but negatively associated with resilience. Furthermore, depressive symptoms and resilience were negatively correlated. All correlation coefficients were statistically significant at the $p<0.001$ level.

\section{Direct Effects of Peer Victimization and Resilience on Depressive Symptoms}

Model 1 produced estimates of factor loadings and error variances for linear latent variables without an interaction term (Figure 1).

Net of demographic background (ie., gender and grade), both resilience and peer victimization were associated with depressive symptoms. In addition, peer victimization was positively linked to depressive symptoms $(\beta=0.25, p<0.001)$, whereas resilience was a negative covariate of depressive symptoms $(\beta=-0.63$, $p<0.001)$. The model provided a good fit to the data: $\chi^{2} / d f=3.05$, TLI $=0.97$, CFI $=0.98$, RMSEA $=0.053$. A total of about $62 \%$ of the variance of depressive symptoms was explained by the variables. The residual variance amounted to 0.38 .

\section{Interaction Effects of Resilience and Peer Victimization on Depressive Symptoms}

In Model 2, we added an interaction term as Klein and Moosbrugger (2000) suggested (Figure 2). In this model, peer victimization was significantly and positively associated with depressive symptoms $(B=0.21, S E=0.07, p<0.001)$, whereas resilience was significantly negatively associated with depressive symptoms $(B=-0.84, S E=0.08, p<0.001)$. The model demonstrated a significant interaction effect of peer victimization and resilience on depressive symptoms $(B=-0.29$, $S E=0.07, p<0.001)$. In terms of variance explained, the residual variance was slightly smaller in Model $2(0.22)$ than in Model 1 (0.38).

To facilitate the interpretation of the interaction effects, we computed the simple slope of the regression of peer victimization on depressive symptoms at low (i.e., one $S D$ below the mean), average, and high (i.e., one $S D$ above the mean) values of resilience (Figure 3). Simple slope analysis revealed that the effect of peer victimization on depressive symptoms was positive and statistically significant at low levels of resilience $(B=0.41, S E=0.08, p<0.001)$ and average levels of resilience $(B=0.21, S E=0.07, p<0.001)$. However, at high levels of resilience, the association between peer victimization and

TABLE 1 | Descriptive statistics for peer victimization, resilience and depressive symptoms.

\begin{tabular}{|c|c|c|c|c|c|}
\hline & Overall & $\begin{array}{l}\text { Migrant children } \\
\text { in public school }\end{array}$ & $\begin{array}{l}\text { Migrant children in } \\
\text { private migrant school }\end{array}$ & $t$ & $p$ \\
\hline$N(\%)$ & $721(100 \%)$ & $384(53.3 \%)$ & 337 (46.7\%) & & \\
\hline \multicolumn{6}{|l|}{ Dependent variables } \\
\hline Depressive symptom & $1.81(0.46)$ & $1.74(0.49)$ & $1.88(0.39)$ & 4.39 & 0.00 \\
\hline \multicolumn{6}{|l|}{ Independent variables } \\
\hline physical victimization & $1.81(0.69)$ & $1.77(0.75)$ & $1.84(0.61)$ & 1.45 & 0.15 \\
\hline relational victimization & $1.39(0.50)$ & $1.36(0.55)$ & $1.42(0.45)$ & 1.79 & 0.07 \\
\hline verbal victimization & $1.66(0.64)$ & $1.60(0.69)$ & $1.73(0.56)$ & 2.76 & 0.01 \\
\hline property victimization & $1.49(0.61)$ & $1.43(0.62)$ & $1.57(0.61)$ & 2.94 & 0.00 \\
\hline social resources & $3.45(0.79)$ & $3.60(0.86)$ & $3.26(0.65)$ & -8.57 & 0.00 \\
\hline personal assets & $3.54(0.69)$ & $3.74(0.75)$ & $3.32(0.53)$ & -6.00 & 0.00 \\
\hline
\end{tabular}


TABLE 2 | Correlation coefficients among observed variables.

\begin{tabular}{|c|c|c|c|c|c|c|c|c|c|}
\hline & 1 & 2 & 3 & 4 & 5 & 6 & 7 & 8 & 9 \\
\hline 1 Physical victimization & 1 & & & & & & & & \\
\hline 2 Relational victimization & 0.42 & 1 & & & & & & & \\
\hline 3 Verbal victimization & 0.57 & 0.69 & 1 & & & & & & \\
\hline 4 Property victimization & 0.45 & 0.54 & 0.57 & 1 & & & & & \\
\hline 5 Personal assets & -0.21 & -0.24 & -0.25 & -0.21 & 1 & & & & \\
\hline 6 Social resource & -0.33 & -0.37 & -0.42 & -0.30 & 0.56 & 1 & & & \\
\hline 7 Depressive factor 1 & 0.33 & 0.38 & 0.41 & 0.31 & -0.47 & -0.54 & 1 & & \\
\hline 8 Depressive factor2 & 0.26 & 0.40 & 0.40 & 0.30 & -0.34 & -0.45 & 0.60 & 1 & \\
\hline 9 Depressive factor3 & 0.30 & 0.42 & 0.41 & 0.30 & -0.45 & -0.50 & 0.70 & 0.64 & 1 \\
\hline
\end{tabular}

Depressive factor 1 - Depressive factor 3 = three parcels of depressive symptoms. All bivariate coefficients are statistically significant at 0.001 level.

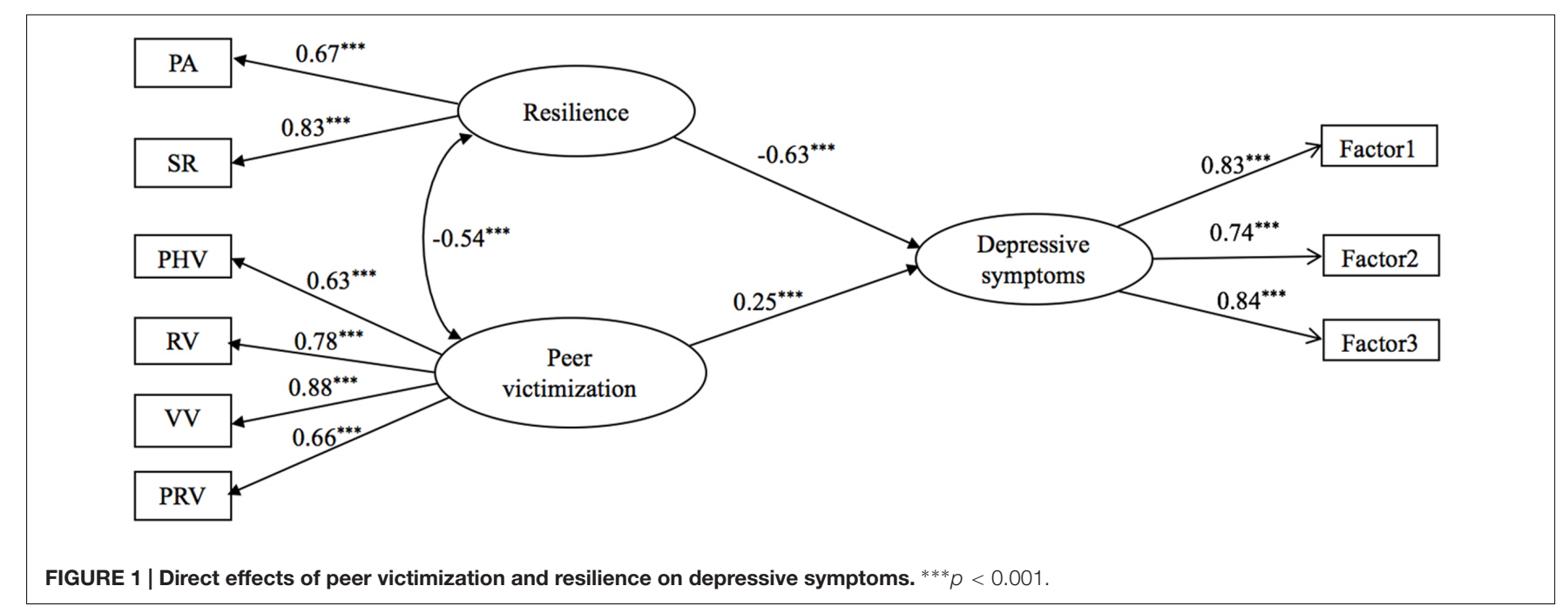

depressive symptoms was non-significant $(B=0.01, S E=0.08$, $p=0.90)$.

\section{Multiple Group Analysis}

Lastly, we used multiple group analysis to examine whether the interaction model differed significantly between the two groups of migrant children (i.e., private migrant school vs. public school). We first compared a model in which all structural paths were freely estimated with a model in which all structural paths were constrained to be equal. Constraining the model resulted in a statistically significant worsening of overall model fit $\left(\Delta \chi^{2}\right.$ $(3)=12.88, p<0.01)$. Therefore, we compared a model in which all structural paths were freely estimated between the two groups with a model in which we constrained only one of the three structural paths (i.e., two main effects, one interaction effect). The results indicated that the main effects of peer victimization $\left(\Delta \chi^{2}(1)=6.54, p<0.05\right)$ and resilience $\left(\Delta \chi^{2}(1)=6.66\right.$, $p<0.01)$ on depressive symptoms were significantly different for the two groups. Specifically, children enrolled in migrant schools displayed a significantly stronger association between peer victimization and depressive symptoms $(B=0.47, S E=0.15$, $p<0.001)$ than children enrolled in traditional public schools $(B=0.09, S E=0.11, p=0.39)$. Furthermore, resilience had a significantly weaker predictive effect on depressive symptoms for children enrolled in migrant schools $(B=-0.67, S E=0.16$, $p<0.001)$ than for children enrolled in traditional public schools $(B=-2.41, S E=0.84, p<0.01)$. However, When we compared the unconstrained model and a model in which only the path pertaining to the interaction effect was constrained, we found no significant difference between the two models $\left[\Delta \chi^{2}(1)=0.77\right.$, $p=0.38$ ], indicating the interaction effect did not differ by children group.

\section{DISCUSSION}

The goal of this study was to examine the relationship between peer victimization and depressive symptoms among rural-tourban migrant Chinese children and to investigate the role of resilience in modifying this relationship. First of all, our findings indicate that peer victimization is directly associated with depressive symptoms-increases in harassment, bullying, and other forms of peer victimization were linked with a greater number of symptoms of depression. This finding is consistent with previous studies (Ji et al., 2011; Zhang et al., 2009; Garnefski and Kraaij, 2014) but extends the link between peer victimization and depression to a new populationrural-to-urban Chinese migrant children. While all children 


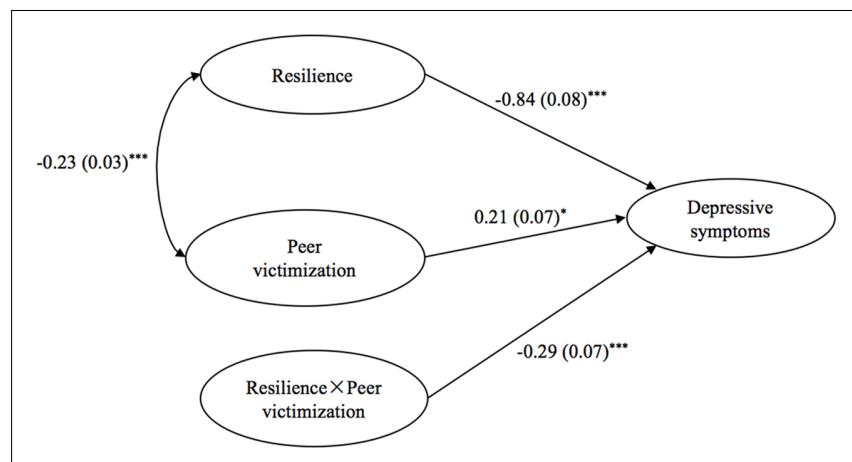

FIGURE 2 | Latent variable interaction model of peer victimization, resilience and depression. $* p<0.05 ;{ }^{* * *} p<0.001$.

encounter periods of transition, migrant children face particular psychosocial challenges as they adjust to the loss of one community while experiencing rapid immersion into another. As "outsiders" within their new social environments, rural-to-urban migrant children report high rates of peer victimization, and these victimization experiences should be taken seriously given the wide range of negative effects of bullying (Lee, 2011). Parents, caregivers, and educators should be aware of the increased risk for victimization and be vigilant for signs of depression, including sadness, social withdrawal, and changes in mood, appetite, and sleep (American Psychiatric Association, 2013). Our findings also suggest that links between victimization and depression are evident in early adolescence for this population.
Peer relationships take on increased importance during this period, and peer victimization may be particularly detrimental to psychological health at this time (Chen et al., 2009; Wang and Mesman, 2015; Hamilton et al., 2016).

Secondly, our findings suggest that resilience moderates the association between peer victimization and depressive symptoms for rural-to-urban Chinese migrant children, such that the negative effects of peer victimization on depressive symptoms are reduced as resilience increases. Resilience may play a vital role in helping bullied children reduce their risk for depression and maintain psychosocial wellbeing. The results provide support for a protective factor model of resilience that suggests that resilience factors operate in an interactive and synergistic fashion to moderate the negative effects of risks (Fergus and Zimmerman, 2005; Zimmerman et al., 2013). Children who have strong external support networks, are able to regulate their emotions, and are competent problem solvers may fare better in the face of peer victimization (Lee and Cranford, 2008; Zhao and Zhao, 2015). Therefore, efforts to build strong support systems and improve coping skills for migrant children may be an effective way to counteract negative social experiences. Resilience-based interventions designed to improve the ability of migrant children to cope with daily challenges, manage negative cognitions, and maintain a hope for the future may be useful in equipping this population with the "ordinary magic" of resilience (Masten, 2001).

Finally, exploratory analyses suggest that the mechanisms impacting the relationships between peer victimization, depression, and resilience may differ depending upon school setting. The study's sample consisted of rural-to-urban migrant

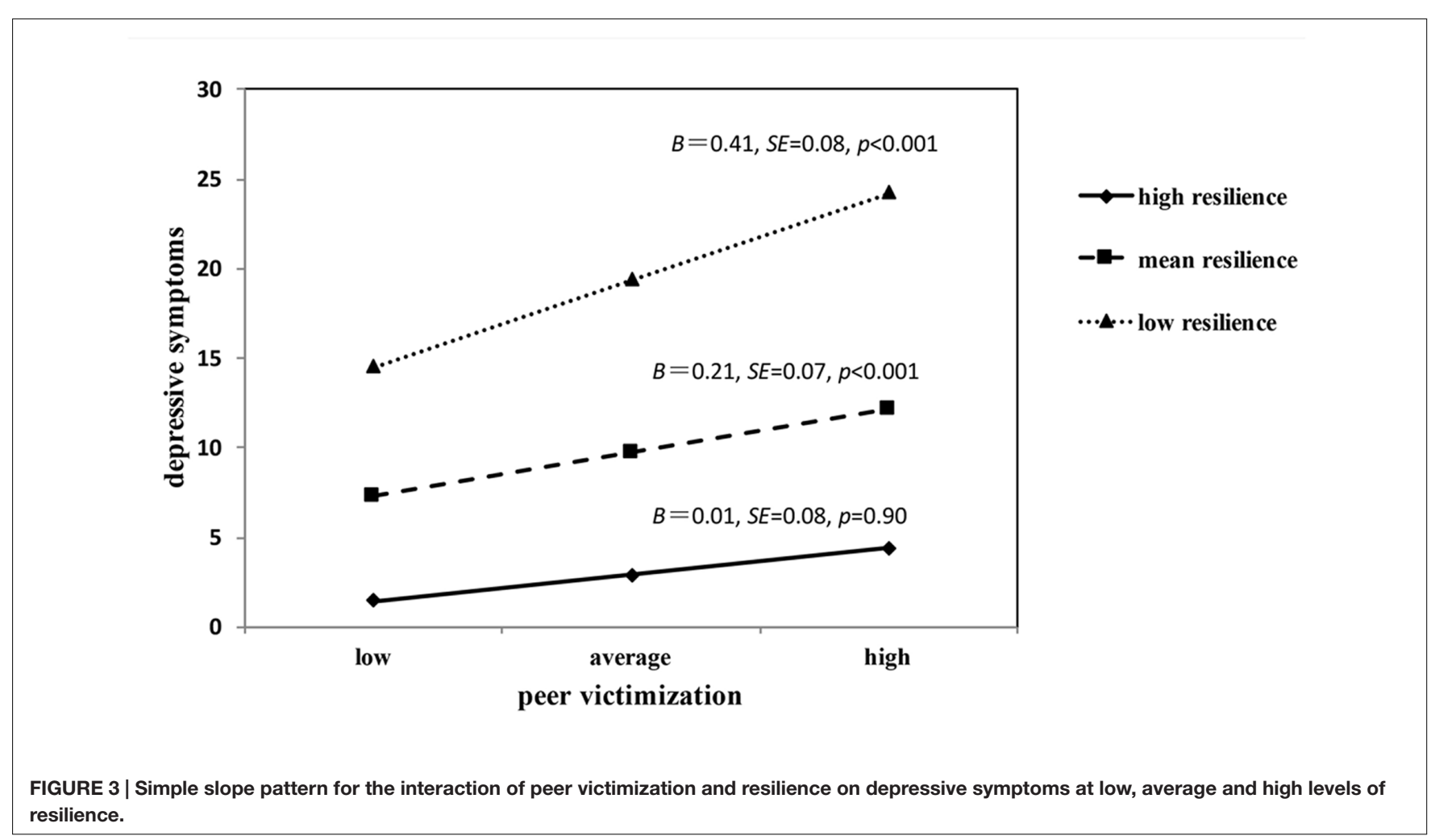


children recruited from two settings: traditional public schools and a private migrant school. Findings suggest that the link between peer victimization and depressive symptoms was stronger for children enrolled in migrant schools, and that resilience provided weaker "defense" against depression for this group. In contrast, enrollment in a traditional public school seemed to offer a level of psychosocial protection for migrant children, even when accounting for demographic characteristics like socio-economic status. This is the second study to identify that public school attendance may actually serve a protective role for migrant children. Gao et al. (2015) found that despite concerns that attending school with non-migrant children could increase opportunity for victimization, public school enrollment for migrant children was actually linked with improved mental health across a wide variety of psychological outcomes. Several mechanisms could account for this, including characteristics of the school and impacts on the acculturation process. School climate has been found to have a major impact on children's mental health (Thapa et al., 2012), and characteristics of Chinese public schools, including their superior infrastructure, greater financial support, strong faculty training, low teacher turnover, and comprehensive curricula may provide a better climate for vulnerable students. Secondly, immersion in the public schools may speed the acculturation process for newly arrived migrant children. Public schools offer better educational resources and more opportunities to connect with the host culture, which may in turn promote children's social adaptation (Gao et al., 2015). In contrast, migrant schools are usually located on the outskirts of cities and served by rural, poorly qualified teachers, limiting the ability of migrant children to interact with people from their new city (Wang, 2008). Given the likelihood of migrant children to also reside in isolated, segregated migrant communities, public schools may be a key element in facilitating a healthy transition to the new urban environment.

China's urban, informal migrant school system has exploded in the past decade, and research is critically needed to explore the impacts-both academic and psychosocial-of school setting for this vulnerable population. Our analysis suggests that the migrant school experience may increase psychosocial risk, with migrant school attendees reported higher levels of victimization, more symptoms of depression, and lower levels of resilience than migrant children enrolled in traditional public schools. The experience of attending a separate school for new migrants to Beijing may highlight the social vulnerability of this population and contribute to feelings of isolation and "otherness." Future comparative studies are needed to explore the impact of the migrant school experience on psychosocial wellbeing and identify opportunities to improve the psychological health of the children who are relegated to this alternative, inequitable educational experience.

Future studies are also needed to tease apart resilience as a broad construct in order to identify sub-factors that may particularly effective in promoting positive outcomes for these youth, including close connections with others. According to Bronfenbrenner (1979), interpersonal relationships are the most important source of influence within a child's immediate environment (i.e., the microsystem). Thus relationships with parents, teachers, and peers yield significant power to promote or hinder a child's socio-emotional development and may offer promise in reducing risk and promoting positive outcomes for this population.

There are several limitations to the current study that warrant discussion. First, the sample consisted of migrant children from one Beijing district, thus limiting the ability of findings to generalize to migrants from other areas. Future studies could also be improved by recruiting a sample of non-migrant children who have moved within an urban area to serve as a comparison group so that the unique effects of the migrant acculturation experience could be better understood (Tucker and Long, 1998; Temple and Reynolds, 1999). Findings could also be strengthened if future studies evaluate key variables through additional methods besides self-report, including parent and teacher evaluations and/or direct observations of child behavior.

Despite these limitations, our findings are informative on at least three levels. First, employing a latent variable interaction model helps to overcome measurement error problems inherent in non-experimental data and thus produces a richer picture of the interactive nature of resilience than traditional statistical approaches (Trautwein et al., 2012; Hukkelberg et al., 2014). The study also provides information on the relationship between peer victimization and depressive symptoms and supports the development of resilience-focused interventions for children who are at-risk of peer victimization. Finally, the study contributes to an emerging body of literature on the psychosocial impact of the rural-to-urban migration experience of children in China and highlights the need for additional knowledge and resources to support this vulnerable population.

\section{AUTHOR CONTRIBUTIONS}

ZY wrote the first draft of the manuscript and assisted in study design, data collection, and data analyses. LC helped design the study and oversaw data collection. SH drafted the work and revised it critically for important intellectual content. HG assisted in study design and oversaw statistical analysis. XL revised the work critically for important intellectual content and assisted in study design. DL was the principal investigator of the study and led the study. All of the authors participated in the final approval of the version to be published and agreed to be accountable for all aspects of the work.

\section{ACKNOWLEDGMENTS}

The authors wish to thank the "Major Projects of the National Social Science Foundation of China (15ZDB138)" and "Supporting Program for New Century Excellent Talents in University (NCET-13-0056) of the Ministry of Education of China" for financial support for the study and the students who participated in this research project: Shaobing Su, Xiaoyenan Xu. 


\section{REFERENCES}

All-China Women's Federation (2013). The Research Report of Left-Behind Children and Migrant Children in Rural China. Chongqing: Southwest China Normal University Press.

American Psychiatric Association (2013). Diagnostic and Statistical Manual of Mental Disorders, 5th Edn. Washington, DC: Author.

Beijing Municipal Bureau of Statistics and Nbs Survey Office in Beijing (2015). Beijing Statistical Yearbook. Beijing: China Statistics Press.

Berry, J. W. (2003). "Conceptual approaches to acculturation," in Acculturation: Advances in Theory, Measurement and Applied Research, eds K. Chun, P. Balls-Organista, and G. Marin (Washington, DC: APA Press), 17-37.

Berry, J. W., Phinney, J. S., Sam, D. L., and Vedder, P. (2006). Immigrant youth: acculturation, identity, and adaptation. Appl. Psychol. Int. Rev. 55, 303-332. doi: 10.1111/j.1464-0597.2006.00256.x

Bonanno, G. A. (2004). Loss, trauma, and human resilience: have we underestimated the human capacity to thrive after extremely aversive events? Am. Psychol. 59, 20-28. doi: 10.1037/0003-066X.59.1.20

Bond, L., Carlin, J. B., Thomas, L., Rubin, K., and Patton, G. (2001). Does bullying cause emotional problems? A prospective study of young teenagers. $\mathrm{Br}$. Med. J. 323, 480-484. doi: 10.1136/bmj.323.7311.480

Bronfenbrenner, U. (1979). The Ecology of Human Development: Experiments by Nature and Design. Cambridge, MA: Harvard University Press.

Bronfenbrenner, U. (1989). "Ecological systems theory," in Annals of Child Development, Vol. 6, ed. R. Vasta (Greenwich, CT: JAI Press), 197-249.

Campbell-Sills, L., Cohan, S. L., and Stein, M. B. (2006). Relationship of resilience to personality, coping, and psychiatric symptoms in young adults. Behav. Res. Ther. 44, 585-599. doi: 10.1016/j.brat.2005.05.001

Chang, Y., and Edwards, J. K. (2015). Examining the relationships among selfefficacy, coping, and job satisfaction using social career cognitive theory: an SEM analysis. J. Career Assess. 23, 35-47. doi: 10.1177/1069072714 523083

Chen, L., Su, S., Li, X., Tam, C. C., and Lin, D. (2014). Perceived discrimination, schooling arrangements and psychological adjustments of rural-to-urban migrant children in beijing, china. Health Psychol. Behav. Med. 2, 713-722. doi: 10.1080/21642850.2014.919865

Chen, X., Wang, L., and Wang, Z. (2009). Shyness-sensitivity and social, school, and psychological adjustment in rural migrant and urban children in China. Child Dev. 80, 1499-1513. doi: 10.1111/j.1467-8624.2009. 01347.x

Chen, Y., and Feng, S. (2013). Access to public schools and the education of migrant children in China. China Econ. Rev. 26, 75-88. doi: 10.1016/j.chieco.2013.04.007

Cole, D. A., Martin, N. C., Sterba, S. K., Sinclair-McBride, K., Roeder, K. M., Zelkowitz, R., et al. (2014). Peer victimization (and harsh parenting) as developmental correlates of cognitive reactivity, a diathesis for depression. J. Abnorm. Psychol. 123, 336-349. doi: 10.1037/a0036489

Crick, N. R., and Bigbee, M. A. (1998). Relational and overt forms of peer victimization: a multiinformant approach. J. Consult. Clin. Psychol. 66, 337-347. doi: 10.1037/0022-006X.66.2.337

Diler, R. S., Avci, A., and Seydaoglu, G. (2003). Emotional and behavioural problems in migrant children. Swiss Med. Wkly. 133, 16-21.

Dong, H. (2007). The Characteristics of Peer Victimization from Age 3 to 5 and Its Relationships with Children's Coping Strategies. Doctoral thesis, Shandong Normal University, Shandong.

Due, P., Damsgaard, M. T., Lund, R., and Holstein, B. E. (2009). Is bullying equally harmful for rich and poor children? A study of bullying and depression from age 15 to 27. Eur. J. Public Health 19, 464-469. doi: 10.1093/eurpub/ckp099

Evans, C. B. R., Smokowski, P. R., and Cotter, K. L. (2014). Cumulative bullying victimization: An investigation of the dose-response relationship between victimization and the associated mental health outcomes, social supports, and school experiences of rural adolescents. Child. Youth Serv. Rev. 44, 256-264. doi: 10.1016/j.childyouth.2014.06.021

Fendrich, M., Weissman, M. M., and Warner, V. (1990). Screening for depressive disorder in children and adolescents: validating the center for epidemiologic studies depression scale for children. Am. J. Epidemiol. 131, 538-551.

Fergus, S., and Zimmerman, M. A. (2005). Adolescent resilience: a framework for understanding healthy development in the face of risk. Annu. Rev.
Public Health 26, 399-419. doi: 10.1146/annurev.publhealth.26.021304. 144357

Fincham, D. S., Altes, L. K., Stein, D. J., and Seedat, S. (2009). Posttraumatic stress disorder symptoms in adolescents: risk factors versus resilience moderation. Compr. Psychiatry 50, 193-199. doi: 10.1016/j.comppsych.2008. 09.001

Gao, Q., Li, H., Zou, H., Cross, W., Ran, B., and Liu, Y. (2015). The mental health of children of migrant workers in Beijing: the protective role of public school attendance. Scand. J. Psychol. 56, 384-390. doi: 10.1111/sjop.12232

Garmezy, N. (1985). The NIMH-Israeli high-risk study: commendation, comments, and cautions. Schizophr. Bull. 11, 349-353. doi: 10.1093/schbul/ 11.3.349

Garnefski, N., and Kraaij, V. (2014). Bully victimization and emotional problems in adolescents: moderation by specific cognitive coping strategies? J. Adolesc. 37, 1153-1160. doi: 10.1016/j.adolescence.2014.07.005

Ghoul, A., Niwa, E. Y., and Boxer, P. (2013). The role of contingent self-worth in the relation between victimization and internalizing problems in adolescents. J. Adolesc. 36, 457-464. doi: 10.1016/j.adolescence.2013.01.007

Goodburn, C. (2009). Learning from migrant education: a case study of the schooling of rural migrant children in Beijing. Int. J. Educ. Dev. 29, 495-504. doi: 10.1016/j.ijedudev.2009.04.005

Gu, M., Zheng, X., and Qiu, L. (2010). A review of psychological research on migrant children. Psychol. Sci. 33, 910-912.

Guo, Z. (2007). The use of anti-discriminatory practice of social work for improving migrant children's mental health. J. South. Yangtze Univ. 6, 35-38.

Hamilton, J. L., Kleiman, E. M., Rubenstein, L. M., Stange, J. P., Flynn, M., Abramson, L. Y., et al. (2016). Deficits in emotional clarity and vulnerability to peer victimization and internalizing symptoms among early adolescents. J. Youth Adolesc. 45, 183-194. doi: 10.1007/s10964-0150260-x

Hawker, D. S., and Boulton, M. J. (2000). Twenty years' research on peer victimization and psychosocial maladjustment: a meta-analytic review of crosssectional studies. J. Child Psychol. Psychiatry 41, 441-455. doi: 10.1111/14697610.00629

Hong, J. S., and Espelage, D. L. (2012). A review of research on bullying and peer victimization in school: an ecological system analysis. Aggress. Violent Behav. 17, 311-322. doi: 10.1016/j.avb.2012.03.003

Hu, H., Lu, S., and Huang, C. C. (2014). The psychological and behavioral outcomes of migrant and left-behind children in China. Child. Youth Serv. Rev. 46, 1-10. doi: 10.1016/j.childyouth.2014.07.021

Hu, Y., and Gan, Y. (2008). Development and psychometric validity of the resilience scale for Chinese adolescents. Acta Psychol. Sin. 40, 902-912. doi: 10.3724/SP.J.1041.2008.00902

Hukkelberg, S. S., Hagtvet, K. A., and Kovac, V. B. (2014). Latent interaction effects in the theory of planned behaviour applied to quitting smoking. Br. J. Health Psychol. 19, 83-100. doi: 10.1111/bjhp.12034

Ji, L., Chen, L., Xu, F., Zhao, S., and Zhang, W. (2011). A longitudinal analysis of the association between peer victimization and patterns of psychosocial adjustment during middle and late childhood. Acta Psychol. Sin. 43, 1151-1162. doi: 10.3724/SP.J.1041.2011.01151

Klein, A., and Moosbrugger, H. (2000). Maximum likelihood estimation of latent interaction effects with the LMS method. Psychometrika 65, 457-474. doi: 10.1007/BF02296338

Klomek, A. B., Marrocco, F., Kleinman, M., Schonfeld, I. S., and Gould, M. S. (2007). Bullying, depression, and suicidality in adolescents. J. Am. Acad. Child Adolesc. Psychiatry 46, 40-49. doi: 10.1097/01.chi.0000242237. 84925.18

Landis, R. S., Beal, D. J., and Tesluk, P. E. (2000). A comparison of approaches to forming composite measures in structural equation models. Organ. Res. Methods 3, 186-207. doi: 10.1177/109442810032003

Lee, C. H. (2011). An ecological systems approach to bullying behaviors among middle school students in the United States. J. Interpers. Violence 26, 1664-1693. doi: 10.1177/0886260510370591

Lee, H. H., and Cranford, J. A. (2008). Does resilience moderate the associations between parental problem drinking and adolescents' internalizing and externalizing behaviors?: A study of Korean adolescents. Drug Alcohol Depend. 96, 213-221. doi: 10.1016/j.drugalcdep.2008.03.007 
Li, X., Chi, P., Sherr, L., Cluver, L., and Stanton, B. (2015). Psychological resilience among children affected by parental HIV/AIDS: a conceptual framework. Health Psychol. Behav. Med. 3, 217-235. doi: 10.1080/21642850.2015. 1068698

Li, X., Zou, H., Wang, R., and Dou, D. (2008). The developmental characteristics of temporary migrant children's self-esteem and its relation to learning behavior and teacher-student relationship in Beijing. Psychol. Sci. 31, 909-913.

Liang, Z., and Chen, Y. P. (2007). The educational consequences of migration for children in China. Soc. Sci. Res. 36, 28-47. doi: 10.1016/j.ssresearch.2005.09.003

Lin, X., Fang, X., Liu, Y., and Lan, J. (2009). The effect mechanism of stigma perception on mental health among migrant children in Beijing. Acta Psychol. Sin 41, 967-979. doi: 10.3724/SP.J.1041.2009.00967

Little, T. D., Cunningham, W. A., Shahar, G., and Widaman, K. F. (2002). To parcel or not to parcel: exploring the question, weighing the merits. Struct. Equ. Modeling 9, 151-173. doi: 10.1207/S15328007SEM0902_1

Liu, J., Bullock, A., and Coplan, R. J. (2014). Predictive relations between peer victimization and academic achievement in Chinese children. Sch. Psychol. Q. 29, 89-98. doi: $10.1037 /$ spq0000044

Luther, S. S., Cicchetti, D., and Becker, B. (2000). The construct of resilience: a critical evaluation and guidelines for future work. Child Dev. 71, 543-562. doi: $10.1111 / 1467-8624.00164$

Mao, Z., and Zhao, X. (2012). The effects of social connections on self-rated physical and mental health among internal migrant and local adolescents in Shanghai, China. BMC Public Health 12:97. doi: 10.1186/1471-2458-12-97

Masten, A. S. (2001). Ordinary magic. Am. Psychol. 56, 227-238. doi: 10.1037/0003066X.56.3.227

Masten, A. S., and Narayan, A. J. (2012). Child development in the context of disaster, war, and terrorism: pathways of risk and resilience. Annu. Rev. Psychol. 63, 227-257. doi: 10.1146/annurev-psych-120710-100356

Muthén, L. K., and Muthén, B. O. (1998-2012). Mplus User's Guide. Los Angeles, CA: Muthén and Muthén.

Mynard, H., and Joseph, S. (2000). Development of the multidimensional peervictimization scale. Aggress. Behav. 26, 169-178. doi: 10.1002/(SICI)10982337(2000)26:23.0.CO;2-A

Peng, L., Zhang, J., Li, M., Li, P., Zhang, Y., Zuo, X., et al. (2012). Negative life events and mental health of Chinese medical students: the effect of resilience, personality and social support. Psychiatry Res. 196, 138-141. doi: 10.1016/j.psychres.2011.12.006

Phinney, J. (2003). "Ethnic identity and acculturation," in Acculturation: Advances in Theory, Measurement, and Applied Research, eds K. Chun, P. Organista, and G. Marin (Washington, DC: American Psychological Association), 63-81.

Roeder, K. M., Cole, D. A., Sinclair, K. R., Dukewich, T. L., Preacher, K. J., Felton, J. W., et al. (2014). Sensitive periods for the effect of peer victimization on selfcognition: moderation by age and gender. Dev. Psychopathol. 26, 1035-1048. doi: $10.1017 /$ S0954579414000601

Schwartz, D., Gorman, A. H., Nakamoto, J., and Toblin, R. L. (2005). Victimization in the peer group and children's academic functioning. J. Educ. Psychol. 97, 425-435. doi: 10.1037/0022-0663.97.3.425

Seals, D., and Young, J. (2003). Bullying and victimization: prevalence and relationship to gender, grade level, ethnicity, self-esteem, and depression. Adolescence 38, 735-747.

Sentse, M., Dijkstra, J. K., Salmivalli, C., and Cillessen, A. H. (2013). The dynamics of friendships and victimization in adolescence: a longitudinal social network perspective. Aggress. Behav. 39, 229-238. doi: 10.1002/ab.21469

Sinclair, K. R., Cole, D. A., Dukewich, T., Felton, J., Weitlauf, A. S., Maxwell, M. A., et al. (2012). Impact of physical and relational peer victimization on depressive cognitions in children and adolescents. J. Clin. Child Adolesc. Psychol. 41, 570-583. doi: 10.1080/15374416.2012.704841

Snyder, J., Brooker, M., Patrick, M. R., Snyder, A., Schrepferman, L., and Stoolmiller, M. (2003). Observed peer victimization during early elementary school: continuity, growth, and relation to risk for child antisocial and depressive behaviour. Child Dev. 74, 1881-1898. doi: 10.1046/j.14678624.2003.00644.x

Tan, Q. (2010). School bullying and school adjustment among urban migrant children in China. Theory Pract. Contemp. Educ. 2, 94-96.

Temple, J. A., and Reynolds, A. J. (1999). School mobility and achievement: longitudinal findings from an urban cohort. J. Sch. Psychol. 37, 355-377. doi: $10.1016 / 50022-4405(99) 00026-6$
Thapa, A., Cohen, J., Higgins-D’Alessandro, A., and Guffey, S. (2012). School Climate Research Summary: August 2012. School Climate Brief, No. 3. New York, NY: National School Climate Center.

The Ministry of Education of the People's Republic of China (2014). Education Statistics Yearbook of China. Beijing: People's Education Press.

Trautwein, U., Marsh, H. W., Nagengast, B., Ludtke, O., Nagy, G., and Jonkmann, K. (2012). Probing for the multiplicative term in modern expectancy-value theory: a latent interaction modeling study. J. Educ. Psychol. 104, 763-777. doi: 10.1037/a0027470

Tucker, C. J., and Long, L. (1998). “moving on”: residential mobility and children's school lives. Soc. Educ. 71, 111-129. doi: 10.2307/2673244

Wang, L. (2008). The marginality of migrant children in the urban chinese educational system. Br. J. Soc. Educ. 29, 691-703. doi: $10.1080 / 01425690802423361$

Wang, L., and Mesman, J. (2015). Child development in the face of rural-to-urban migration in China a meta-analytic review. Pers. Psychol. Sci. 10, 813-831. doi: 10.1177/1745691615600145

Wang, Z., Zhang, J., Pan, Y., and Gao, J. (2014). Effects of social support on depressive in migrant children: the mediating role of resilience. Chin. J. Clin. Psychol. 22, 311-314.

Werner, E., and Smith, R. (1982). Vulnerable but Invincible: A Study of Resilient Children. New York, NY: McGraw-Hill.

Wingo, A. P., Wrenn, G., Pelletier, T., Gutman, A. R., Bradley, B., and Ressler, K. J. (2010). Moderating effects of resilience on depression in individuals with a history of childhood abuse or trauma exposure. J. Affect. Disord. 126, 411-414. doi: $10.1016 /$ j.jad.2010.04.009

Wong, D. F., and Song, H. X. (2008). The resilience of migrant workers in Shanghai China: the roles of migration stress and meaning of migration. Int. J. Soc. Psychiatry 54, 715-721. doi: 10.1177/0020764007083877

Wu, Q., Tsang, B., and Ming, H. (2012). Social capital, family support, resilience and educational outcomes of chinese migrant children. Br. J. Soc. Work 44, 636-656. doi: 10.1093/bjsw/bcs139

Zhang, J. J., Li, N. X., and Liu, C. J. (2010). Associations between poor health and school-related behavior problems at the child and family levels: a cross-sectional study of migrant children and adolescents in Southwest Urban China. J. Sch. Health 80, 296-303. doi: 10.1111/j.1746-1561.2010. 00504.x

Zhang, L., and Tian, H. (2014). On the improvement of migrant children's resilience by group counseling. Chin. J. Spec. Educ. 10, 14-19.

Zhang, W. (2002). Prevalence and major characteristics of bullying/victimization among primary and junior middle school children. Acta Psychol. Sin. 34, 387-394.

Zhang, W., Chen, L., Ji, L., Zhang, L., Chen, G., and Wang, S. (2009). Physical and relational victimization, and children's emotional adjustment in middle childhood. Acta Psychol. Sin. 41, 433-443. doi: 10.3724/SP.J.1041.2009. 00433

Zhao, Y., and Zhao, G. (2015). Emotion regulation and depressive symptoms: examining the mediation effects of school connectedness in Chinese late adolescents. J. Adolesc. 40, 14-23. doi: 10.1016/j.adolescence.2014.12.009

Zhu, Q., Fan, F., Zheng, Y., Sun, S., Zhang, L., and Tian, W. (2012). Moderating and mediating effects of resilience between negative life events and depression symptoms among adolescents following the 2008 Wenchuan earthquake in China. Chin. J. Clin. Psychol. 20, 514-517.

Zimmerman, M. A., Stoddard, S. A., Eisman, A. B., Caldwell, C. H., Aiyer, S. M., and Miller, A. (2013). Adolescent resilience: promotive factors that inform prevention. Child Dev. Pers. 7, 215-220. doi: 10.1111/cdep.12042

Conflict of Interest Statement: The authors declare that the research was conducted in the absence of any commercial or financial relationships that could be construed as a potential conflict of interest.

Copyright (c) 2016 Ye, Chen, Harrison, Guo, Li and Lin. This is an open-access article distributed under the terms of the Creative Commons Attribution License (CC BY). The use, distribution or reproduction in other forums is permitted, provided the original author(s) or licensor are credited and that the original publication in this journal is cited, in accordance with accepted academic practice. No use, distribution or reproduction is permitted which does not comply with these terms. 